\title{
Factors Affecting Survival and Growth of Juvenile Freshwater Mussels Cultured in Recirculating Aquaculture Systems
}

\author{
JESS W. JONES* \\ U.S. Fish and Wildlife Service, Department of Fisheries and Wildlife Sciences, \\ Virginia Polytechnic Institute and State University, \\ Blacksburg, Virginia 24061-0321, USA \\ RACHEL A. MAIR \\ Department of Fisheries and Wildlife Sciences, \\ Virginia Polytechnic Institute and State University, Blacksburg, Virginia 24061-0321, USA \\ RiCHARD J. NEVES \\ U.S. Geological Survey, Virginia Cooperative Fish and Wildlife Research Unit, ${ }^{1}$ \\ Department of Fisheries and Wildlife Sciences, Virginia Polytechnic Institute and State University, \\ Blacksburg, Virginia 24061-0321, USA
}

\begin{abstract}
Seasonal differences in glochidial maturity, substrate, and diet were studied to determine how these factors affect the survival and growth of juvenile freshwater mussels. Comparisons were made between juveniles produced in the fall and spring of the year; cultured in sediment, sand, or without substrate; and fed either of two species of small $(5-10-\mu \mathrm{m})$ green algae. The survival and growth of endangered juveniles of oyster mussel Epioblasma capsaeformis were compared with those of a common, seemingly more robust species, the rainbow mussel Villosa iris. The growth of rainbow mussel juveniles was significantly greater than that of oyster mussel juveniles $(P<0.001)$. The survival and growth of oyster mussel juveniles were significantly greater when propagated in the spring, that is, when glochidia were mature and would normally be released, than in fall $(P<0.001)$. Survival and growth of juveniles of both species were significantly greater when they were cultured in a sediment substratum rather than sand or no substratum $(P<0.001)$. No differences $(P>0.05)$ were observed in survival and growth of juveniles fed algal species Neochloris oleoabundans or Nannochloropsis oculata. In the spring of the year, juvenile oyster mussels achieved a survival of $29.6 \%$ and mean length of $664 \mu \mathrm{m}$ at 60 $\mathrm{d}$ of age, whereas at the same age rainbow mussel juveniles exhibited a survival of $25.1 \%$ and a mean length of $1,447 \mu \mathrm{m}$.
\end{abstract}

North America contains the greatest diversity of freshwater mussels in the world, nearly 300 species. However, bivalve mollusks of the superfamily Unionacea are the most imperiled group of animals in the United States, with 213 species $(72 \%)$ listed as endangered, threatened, or of special concern (Williams et al. 1993; Neves 1999). Already, approximately 35 species are considered extinct, representing $12 \%$ of the North American mussel fauna disappearing in the last 100 years, a rate of extinction comparable to estimated faunal losses in tropical rainforests (Ricciardi and Rasmussen

\footnotetext{
1 The Unit is supported jointly by the U.S. Geological Survey, Virginia Department of Game and Inland Fisheries, Wildlife Management Institute, and Virginia Polytechnic Institute and State University.

* Corresponding author: jess_jones@fws.gov
}

Received September 11, 2004; accepted February 15, 2005 Published online June 17, 2005
1999). Most of the endangerment is caused by habitat loss or destruction due to impoundment, sedimentation, water pollution, dredging, and other anthropogenic factors that affect the natural structure and function of free-flowing rivers (Neves et al. 1997; Neves 1999). Without immediate efforts to recover federally protected species in U.S. watersheds, the extinction of additional species is likely. To address the threat of future species losses, biologists at the Freshwater Mollusk Conservation Center at Virginia Polytechnic Institute and State University (Virginia Tech) in Blacksburg, Virginia, have developed techniques to propagate and culture endangered freshwater mussels for release of juveniles into rivers of the Tennessee River drainage.

Propagation and culture of endangered mussel species has been recommended in recovery plans as a strategy to augment existing populations and to reintroduce species to sites within their historic 
ranges. The Tennessee Wildlife Resources Agency, the U.S. Fish and Wildlife Service, and Virginia Tech entered into a multi-year cooperative program to produce, culture, and release juveniles of numerous endangered mussel species into tributaries of the Tennessee River drainage in Tennessee and Virginia. The goals of this project were to augment natural reproduction in extant populations and to release juvenile mussels into historic habitat to expand the range of existing populations. The initial focus is the Clinch, Powell, Hiwassee, and Big South Fork Cumberland rivers, where sufficient broodstock and suitable habitat exist to augment or reestablish populations of rare mussels. Because of high species richness and endemism in these rivers, these watersheds are of national significance for conservation of mussel resources in the United States (Ahlstedt 1991; Neves 1999). The selection of species and release sites was determined by a joint meeting of mussel biologists representing the various funding and cooperating agencies.

Unionacean mussels are filter-feeders that have a unique life history, requiring that their larvae (glochidia) parasitize a fish host to complete their life cycle. Embryos mature into glochidia in the gills of the female mussel. Once mature, the female then releases the glochidia into the water, where they must attach and encyst on the gills, fins, or epidermis of a suitable host fish for metamorphosis to the juvenile stage. Once this transformation is complete, juveniles excyst and drop off the fish host to begin their lives on the bottom of a river or lake. To maximize attachment of glochidia to host fish, some mussel species produce glochidia in packets (conglutinates) or have modified mantle-lures that closely resemble prey of fish, insect larvae and pupae, leeches, and even other fish, all of which seem to attract host fish to the female mussel and her glochidia. Depending on the species, mussel glochidia are brooded in the gills of females during either the winter (bradytictic) or summer (tachytictic). Winter brooders typically release their glochidia in spring and summer, whereas summer brooders release glochidia only in summer.

Gatenby et al. (1997) and O'Beirn et al. (1998) developed methods to culture juvenile freshwater mussels in captivity. However, a clear understanding of factors influencing survival and growth of juvenile mussels was needed to reliably produce endangered juveniles for population augmentation. From 1997 to1999, our attempts to culture juveniles of the oyster mussel Epioblasma capsaefor- mis and other endangered species for more than 30-60 d were unsuccessful. During these culture trials, it became clear that the maturity of the glochidia affects subsequent survival and growth of juveniles. Glochidia removed from female mussels in the fall of the year seemingly lacked full maturity. These glochidia closed slowly or not at all when exposed to salt and contained a greater amount of undifferentiated tissue between the valves. Juveniles propagated in the fall did not pedal-feed as actively as those produced in the spring, and subsequent survival and growth of the former were poor, especially for juveniles of endangered species such as oyster mussels. Other factors affecting survival and growth of juvenile mussels were identified, including control of predators in recirculating aquaculture systems (Zimmerman and Neves 2003), the size of the algae provided as food (Beck and Neves 2003), and inclusion of fine organic sediment $(<200 \mu \mathrm{m})$ in the culture environment (Gatenby et al. 1996, 1997). Thus, the purpose of this study was to experimentally evaluate seasonal viability of glochidia, diet, and substrate size on survival and growth of propagated juvenile mussels. Differences between species were assessed by comparing survival and growth of juveniles of an endangered species, the oyster mussel, with those of a common, seemingly more tolerant mussel species, the rainbow mussel Villosa iris.

\section{Methods}

Propagation of juvenile mussels.-Gravid oyster mussel females were collected by snorkeling and hand-collection at various Clinch River kilometer (CRKM) locations between Wallen Bend (CRKM 309.6) and Frost Ford (CRKM 291.7), Hancock County, Tennessee. Gravid rainbow mussel females were collected from the Little River, Tazewell County, Virginia. Black sculpin Cottus baileyi was used as the host species to transform glochidia of oyster mussels and was collected from the South Fork Holston River, Smyth County, Virginia. Rock bass Ambloplites rupestris was used as the host fish for glochidia of rainbow mussels and was collected from the New River, Montgomery County, Virginia. Both fish species seemingly are suitable hosts and have been used extensively in our laboratory to produce robust juveniles of each respective mussel species, that is, juveniles that are more than 1 year old and 1-2 $\mathrm{mm}$ in length (data available from J. W. Jones). Methods for infestation of host fish generally followed those of Zale and Neves (1982). In fall 2000, glochidia were 
extracted from six oyster mussels and six rainbow mussels and were infested onto the respective host fish in early November. No gravid female oyster mussels were collected in fall 2001, but three gravid females were collected in winter 2002. Glochidia were extracted from these females and infested onto host fish in early January. Glochidia were extracted from six female rainbow mussels in early November 2001. Female oyster mussels collected in fall or winter were not displaying their mantle-pad lure. In spring 2001-2003, six gravid females of both species were collected each year, from which glochidia were extracted in early May. All female oyster mussels collected in spring were actively displaying their mantle-pad lure. Female rainbow mussels were not displaying their mantle lures when collected; however, this species is known to display predominately at night and in low light conditions. Common and scientific names follow Nelson et al. (2004) for fishes and Turgeon et al. (1998) for mussels.

Determination of glochidial maturity.-Glochidia were tested for maturity by exposing a subsample $(N=20-30)$ of the glochidia from each female mussel to a dilute salt solution $(0.05-0.10 \mathrm{mg}$ $\mathrm{NaCl} / \mathrm{L}$ ) for 5-10 s and observing the valve (larval shell) closing response. The glochidial brood of a female mussel was considered immature based on the following criteria: (1) more than $10 \%$ of glochidia exposed to $\mathrm{NaCl}$ solution failed to close their valves, (2) the closing response of the glochidia was slow (>1 s), (3) vitelline membrane was present on the glochidia, and (4) a conspicuous amount of undifferentiated tissue was visible between valves. Undifferentiated tissue is presumably lipid reserves and appears as "fatty" amorphous material between the glochidial valves close to the larval adductor muscle (Tankersley 2000). Descriptions and photomicrographs of lipid deposits on a glochidium are shown in Tankersley (2000). In our experience, mature glochidia contain less undifferentiated tissue between the valves, and the adductor muscle appears unobstructed and readily visible.

Culture of juvenile mussels. - Newly metamorphosed (1-d-old) juvenile mussels were used in all trials. Entire batches of juveniles were counted and cultured to assess the brood quality of juveniles propagated in fall versus those propagated in spring. Fall trials were conducted in 2000 and 2001; spring trials were conducted in 2001, 2002, and 2003.

Juvenile mussels were cultured in containers constructed of polyvinyl chloride (PVC) pipe 23 $\mathrm{cm}$ in diameter and $6 \mathrm{~cm}$ high; 100- $\mu \mathrm{m}$-mesh screen was glued to one end of the PVC pipe as a bottom. Fine sediment was collected from the South Fork Holston River at Buller Fish Hatchery, near Marion, Virginia. The sediment was sieved to retain particle sizes smaller than $200 \mu \mathrm{m}$. Fine sediment was placed into the containers to a depth of 3-5 mm. Sand collected from the New River, Montgomery County, Virginia, was sieved to obtain particle sizes of $200-300 \mu \mathrm{m}$ and placed into containers to a depth of 3-5 mm. Before being placed in culture dishes, sediment and sand were autoclaved to kill any predators such as flatworms and dipteran larvae. After sediments were autoclaved, they were aerated with an air stone for 2$3 \mathrm{~d}$ to help oxidize and remove excess organic acids.

Our recirculating aquaculture system (RAS) for juvenile mussels resembled that of O'Beirn et al. (1998). Each RAS consisted of two 225-L plastic livestock feed troughs set side by side as raceways. Juveniles of each mussel species were held separately in one of the two troughs. A $0.5 \mathrm{hp}$ (1 horsepower $[\mathrm{hp}]=746 \mathrm{~W}$ ) centrifugal pump recirculated water through the raceways, which drained by gravity through PVC piping into a sump. A 50: 50 mixture of conditioned (dechlorinated) municipal water and well water was used in the recirculating culture system. All trials were conducted with four RAS units set up at the Freshwater Mollusk Conservation Center at Virginia Tech.

Juvenile mussels were fed daily with the green alga Neochloris oleoabundans or Nannochloropsis oculata at a concentration of about 30,000 cells/ $\mathrm{mL}$. Algae were grown in $19-\mathrm{L}$ carboys by the methods discussed in Beck (2001) and Hoff and Snell (1999), which require extreme sanitation to eliminate exposure of algae cultures to air- and water-borne contaminants. Juveniles were placed in culture dishes $(N=4$ dishes per substratum type) containing sediment, sand, or no substrate. The mean number of oyster mussel juveniles cultured in sediment was 411 (range $=108-811), 234$ in sand (range $=112-340$ ), and 158 in no substrate (range $=73-263)$. The mean number of rainbow mussel juveniles cultured in sediment was 499 $($ range $=218-971), 291$ in sand (range $=140-$ 578 ), and 324 in no substrate (range $=186-613$ ). Culture dishes for the various substrate conditions were placed side by side on the bottom of each trough; that is, juvenile mussels for all such treatments were cultured together in a RAS. Based on previous culture trials conducted in our laboratory (Jones unpublished data), poor survival and 
TABLE 1.-Mean values (SEs) for selected water chemistry variables in recirculating aquaculture systems for juvenile mussel culture, 2000-2003.

\begin{tabular}{lcrrrr}
\hline \multicolumn{1}{c}{ Variable } & Fall 2000 & \multicolumn{1}{c}{ Fall 2001} & \multicolumn{1}{c}{ Spring 2002 } & \multicolumn{1}{c}{ Spring 2003 } \\
\hline TAN $(\mathrm{mg} / \mathrm{L})$ & $0.25(0.01)$ & $0.30(0.01)$ & $0.23(0.01)$ & $0.27(0.02)$ \\
$\mathrm{NH}_{3}(\mathrm{mg} / \mathrm{L})$ & $0.03(0.00)$ & $0.03(0.00)$ & $0.02(0.01)$ & $0.03(0.00)$ \\
$\mathrm{pH}$ & $8.4(0.05)$ & $8.2(0.03)$ & $8.0(0.04)$ & $8.50(0.04)$ \\
Hardness $\left(\mathrm{CaCO}_{3}[\mathrm{mg} / \mathrm{L}]\right)$ & 196 & $(4.2)$ & $132.8(1.6)$ & $207.0(2.6)$ & $183.0(2.7)$ \\
Alkalinity $\left(\mathrm{CaCO}_{3}[\mathrm{mg} / \mathrm{L}]\right)$ & $150.1(3.4)$ & $91.8(2.2)$ & $150.1(2.0)$ & $147.42(5.5)$ \\
Temperature $\left({ }^{\circ} \mathrm{C}\right)$ & $22.6(0.52)$ & 21.1 & $(0.15)$ & $22.7(0.16)$ & $21.9(0.59)$ \\
\hline
\end{tabular}

growth were anticipated in the fall and in the sand and no substrate treatment conditions; therefore, because of the endangered status of the oyster mussel, fewer juveniles of this species and of rainbow mussels were propagated and used for these treatment conditions. From each substratum type, 20 juveniles per culture dish were measured for length at each sampling interval. Thus, the mean length of juveniles from each RAS $(N=4)$, per substratum type, was compared statistically.

Culture dishes were cleaned every 2 weeks to remove excess algae, bacteria, fungi, and possible predators. The dishes containing fine sediment were cleaned by gently rinsing the juvenile mussels and accumulated algae from the dishes into a $200-\mu \mathrm{m}$ mesh sieve. The contents then were washed in the sieve with conditioned water until most of the algae were removed. Fresh sediment replaced that in the dishes. Culture dishes containing sand and those with no substrate were cleaned by pouring the entire contents into a 200$\mu \mathrm{m}$ mesh sieve. The contents, including juvenile mussels, were gently washed. For all trials, algae that accumulated on the bottom of the raceway were siphoned out every 2 weeks, providing a $50 \%$ water exchange in each RAS. For all trials, juveniles were cultured at cool water temperatures averaging $21-23^{\circ} \mathrm{C}$. Three times each week, water temperature, $\mathrm{pH}$, alkalinity, hardness, total ammonia, and un-ionized ammonia were measured in each RAS (Table 1).

Data analysis.-Survival and growth data were compared among groups of juvenile mussels propagated in either fall or spring and fed either algal diet at 4 - and 8 -week sampling intervals by $t$-test (SAS Institute 2001). Survival and growth of juveniles cultured under different substrate conditions were compared by using analysis of variance (ANOVA). Species comparisons were performed only on juvenile mussels cultured in fine sediment because survival and growth were poor for those cultured in sand or no substratum. The spring 2001 trial was negatively affected by mortality induced by flatworm predation; therefore, data from that trial were excluded from analysis of seasonal viability of juvenile mussels. A spring trial was conducted in 2003 to provide data not collected in spring 2001. Thus, comparisons of seasonal viability of juveniles among treatments involved eight replicated RAS units using combined data from the fall of 2001 and 2002, and eight using combined data from the spring of 2002 and 2003. For treatment effects of species-level differences between oyster mussels and rainbow mussels, comparisons were made separately for juveniles propagated in fall and those propagated in spring; therefore, $N=8$ for each species in both the fall and the spring. Because culture success was clearly greater in sediment, trials examining substrate suitability were limited to data obtained in fall 2000 and spring 2001. Furthermore, comparisons were made separately for juveniles propagated in the fall $(N=4)$ or spring $(N=4)$ because of significant seasonal differences observed in growth and survival. Mean survival and growth rates for all treatments were normally distributed according to the Kolmogorov-Smirnov goodnessof-fit test. Arc-sine transformations were performed on proportion data before statistical analysis. Values for water chemistry parameters in each RAS were compared between trials by ANOVA. Significance of all tests was set at $\alpha=0.05$.

\section{Results}

No statistical differences in survival and growth were detected between juveniles fed $N$. oleoabundans and those fed $N$. oculata, so these data sets were combined for additional treatment comparisons. Generally, no significant differences were detected between data sets obtained in fall of 2000 and fall of 2001, or between spring of 2002 and spring of 2003. However, survival of oyster mussel juveniles was significantly greater $(P<0.05)$ in the spring of 2002 than in spring 2003, at $47.6 \%$ and $11.6 \%$, respectively. Hence, survival and growth for this species in spring 2003 were still significantly greater than that in either trial conducted in the fall. Therefore, data from each of the 
TABLE 2.- Mean (SE) survival and length of juvenile freshwater mussels produced in recirculating aquaculture systems at the Freshwater Mollusk Conservation Center, Blacksburg, Virginia.

\begin{tabular}{|c|c|c|c|c|c|c|c|}
\hline \multirow[b]{2}{*}{ Species } & \multirow[b]{2}{*}{ Season } & \multirow{2}{*}{$\begin{array}{l}\text { Substratum } \\
\text { type }\end{array}$} & \multirow{2}{*}{$\begin{array}{c}\text { Number of } \\
\text { juveniles } \\
\text { at age } 0\end{array}$} & \multicolumn{2}{|c|}{$\%$ Survival } & \multicolumn{2}{|c|}{ Mean length $(\mu \mathrm{m})$} \\
\hline & & & & 4 weeks & 8 weeks & 4 weeks & 8 weeks \\
\hline \multirow[t]{6}{*}{ Epioblasma capsaeformis } & \multirow[t]{3}{*}{ Fall } & Sediment & 4,618 & $19.7(6.2)$ & $1.6 \quad(0.9)$ & $374 \quad(9.2)$ & $410 \quad(25.5)$ \\
\hline & & Sand & 2,108 & $4.8(0.5)$ & 0.0 & $372 \quad(10.6)$ & No survivors \\
\hline & & No substrate & 1,434 & $0.1(0.0)$ & 0.0 & $359 \quad(7.7)$ & No survivors \\
\hline & \multirow[t]{3}{*}{ Spring } & Sediment & 28,225 & $49.3(8.3)$ & $29.6 \quad(8.8)$ & $476 \quad(6.5)$ & $664 \quad(17.2)$ \\
\hline & & Sand & 5,388 & $13.5(5.8)$ & $0.15(0.1)$ & $372 \quad(9.7)$ & $432.5(7.5)$ \\
\hline & & No substrate & 3,612 & $7.7(2.8)$ & 0.0 & $317.6(8.5)$ & No survivors \\
\hline \multirow[t]{6}{*}{ Villosa iris } & \multirow[t]{3}{*}{ Fall } & Sediment & 15,504 & $40.0(6.5)$ & $29.0 \quad(4.9)$ & $498 \quad(20.4)$ & $1,193 \quad(42.0)$ \\
\hline & & Sand & 4,016 & $13.0(1.4)$ & $3.0 \quad(2.4)$ & $393 \quad(14.6)$ & $560 \quad(46.7)$ \\
\hline & & No substrate & 4,515 & $9.0(2.7)$ & $0.75(0.5)$ & $365 \quad(12.5)$ & $538 \quad(58.1)$ \\
\hline & \multirow[t]{3}{*}{ Spring } & Sediment & 24,440 & $34.8(7.6)$ & $25.1 \quad(9.0)$ & $612 \quad(17.7)$ & $1,447 \quad(65.0)$ \\
\hline & & Sand & 5,308 & $7.8(3.2)$ & $4.1 \quad(2.1)$ & $370 \quad(9.5)$ & $617 \quad(50.7)$ \\
\hline & & No substrate & 5,847 & $4.3(1.8)$ & $0.8 \quad(0.5)$ & $361 \quad(7.6)$ & $626 \quad(80.8)$ \\
\hline
\end{tabular}

fall and spring trials for both species were combined for treatment comparisons.

Survival and growth of oyster mussel juveniles were significantly greater $(P<0.001)$ when propagated in the spring of the year, when glochidia were mature and naturally released (Table 2). For example, survival of oyster mussel juveniles cultured in sediment in the spring at 8 weeks was $29.6 \%$ and mean shell length was $664 \mu \mathrm{m}$, whereas for juveniles cultured in the fall, $<2 \%$ remained alive at 8 weeks and mean shell length was only $410 \mu \mathrm{m}$. Moreover, these remaining fall juveniles were in poor condition and died shortly after the experiment was terminated. Furthermore, glochidia removed from oyster mussel females in the fall or winter appeared immature. When exposed to salt solution, these glochidia closed slowly or not at all, a significant amount of undifferentiated tissue was present between the valves, and many were still encased in the vitelline membrane. The mean length of a 1-d-old juvenile oyster mussel was approximately $250 \mu \mathrm{m}$; the mean length of a 60-d-old juvenile was $664 \mu \mathrm{m}$ in the spring; therefore, mean growth was $6.9 \mu \mathrm{m} / \mathrm{d}$.

Survival and growth of rainbow mussel juveniles were not significantly greater when propagated and cultured in the spring $(P>0.05)$. Survival of rainbow mussel juveniles cultured in sediment in the spring was $25.1 \%$ at 8 weeks, and mean shell length was $1,447 \mu \mathrm{m}$ (Table 2). Survival of rainbow mussel juveniles was much greater than that of oyster mussel juveniles during both fall culture trials $(P<0.001$; Table 2$)$. In addition, growth of rainbow mussel juveniles at 8 weeks was three times that of oyster mussel juveniles. The mean length of a 1-d-old rainbow mussel juvenile was $205 \mu \mathrm{m}$, whereas the mean length of a 60-d-old juvenile was $1,447 \mu \mathrm{m}$ in the spring; therefore, the mean growth rate was $20.7 \mu \mathrm{m} / \mathrm{d}$.

Survival and growth of juvenile rainbow mussels and oyster mussels were significantly greater in dishes containing a sediment substratum $(P<$ $0.001)$. Our culture data for rainbow mussels were comparable with those from previous studies (Gatenby et al. 1997; O'Beirn et al. 1998); however, data for oyster mussels represent one of the first successful long-term culture trials for an endangered mussel species in a RAS. Long-term (3060-d) juvenile culture was successful only in dishes containing sediment. In contrast, juveniles cultured in dishes containing sand or no substrate grew slowly and had high overall mortality of mussel species at $60 \mathrm{~d}$ in all trials. No significant differences $(P>0.05)$ were observed in growth and survival of juveniles cultured in sand or without substrate, or between those fed either $N$. oleoabundans or N. oculata.

In spring 2001, survival of juvenile rainbow mussels and oyster mussels was negatively affected by the predacious flatworm Macrostomum sp. in some of the culture dishes. Flatworms were not observed in the RAS until after 4 weeks into the trial; they were probably introduced into the RAS by sediment used for replacement at the 4week sampling interval. These sediments presumably were not thoroughly autoclaved. The predatory effect of the flatworms was immediate and devastating. Many empty shells of otherwise healthy juveniles were observed in some of the culture dishes, and live juveniles were observed in the digestive tract of flatworms. Survival of both mussel species was excellent at 4 weeks for juveniles cultured in sediment; therefore, the majority of the mortality occurred between 4 and 8 
TABLE 3.-Factors affecting survival and growth of propagated juvenile mussels.

\begin{tabular}{|c|c|}
\hline Factor & Requirements \\
\hline $\begin{array}{l}\text { Physiological condition of adult mussels } \\
\text { throughout reproductive cycle, which af- } \\
\text { fects ability to produce high-quality em- } \\
\text { bryos and glochidia }\end{array}$ & $\begin{array}{l}\text { Suitable environmental conditions regarding habitat, food availability, and flow; } \\
\text { absence of diseases; genetics }\end{array}$ \\
\hline Maturity of glochidia & $\begin{array}{l}\text { Glochidia must be removed at appropriate time of year; maturity of glochidia } \\
\text { controlled by river conditions (e.g., seasonal temperatures) and life history of } \\
\text { species }\end{array}$ \\
\hline Species differences in juvenile stage & $\begin{array}{l}\text { Robustness among species may differ as a consequence of the quantity of ener- } \\
\text { gy reserves available for metamorphosis and pedal-feeding life stages, suit- } \\
\text { ability of food types, substratum types, and temperature }\end{array}$ \\
\hline Quality and quantity of food & $\begin{array}{l}\text { Size, nutritional value, and quantity of ration must be adequate to promote sur- } \\
\text { vival and growth }\end{array}$ \\
\hline Water quality & $\begin{array}{l}\text { High water quality must be maintained during grow-out (e.g., removal of excess } \\
\text { algae, water exchanges, dissolved oxygen, and temperature regulation are re- } \\
\text { quired) }\end{array}$ \\
\hline Predation & $\begin{array}{l}\text { Predators (e.g., Dipteran larvae and platyhelminthes) must be eradicated from } \\
\text { culture systems }\end{array}$ \\
\hline Substratum & $\begin{array}{l}\text { Suitable mixtures of sand and fine organic sediments must be present in culture } \\
\text { containers }\end{array}$ \\
\hline
\end{tabular}

weeks. At 8 weeks, survival for both mussel species was very poor in all substrate conditions, ranging from $0.0 \%$ to $11.0 \%$. Because survival in spring 2001 was dramatically reduced by flatworm predation, data from this trial were eliminated from most analyses. The survival and growth values at 4 weeks in spring 2001 were already much greater in sediment than in either the sand or no substrate treatments, leading us to anticipate additional mortality in these latter two substrates. Thus, the 8week values for juveniles cultured in sand or no substrate in spring 2001 may underrepresent actual survival because of flatworm predation (Table 2).

Water chemistry values appeared normal and within ranges suitable for juvenile mussel culture (Table 1). Although significant differences $(P<$ $0.05)$ were observed between trials for hardness and alkalinity, it is unlikely that these parameters influenced survival and growth of juveniles.

\section{Discussion}

The results of this study indicated that development and maturation of glochidia is important for successful culture of juvenile mussels and that optimization of the culture environment is critical. When culture technology is optimized to promote good survival and growth of juvenile mussels, the majority of mortality related to glochidial maturity will probably occur in the first month. Conversely, mortality related to the culture environment will probably begin later, at about 1-2 months of age. Metamorphosis of the glochidium to the juvenile stage on host fish is complex, involving degeneration of various larval structures and the sub- sequent development of juvenile morphology (Fisher and Dimock 2002a,b). Therefore, it is unlikely that successful metamorphosis will occur with an immature glochidium. Moreover, the literature on marine bivalve culture is rich concerning the importance of managing for gamete maturity, broodstock condition, and genetic compatibility between stocks to maximize larval survival (Lannan 1980a-d; Gaffney et al. 1993; Boudry et al. 2002). Thus, we believe that one of the keys to production of viable juveniles is obtaining mature, healthy glochidia. However, biologists should keep in mind that successful propagation and culture of juvenile mussels depends on simultaneous control of many culture factors. Any one suboptimal factor can cause significant juvenile mortality (Table 3 ).

\section{Maturation of Glochidia}

In this study, maturity of glochidia greatly influenced the viability of propagated juvenile oyster mussels from the Clinch River. When oyster mussel glochidia were extracted in the fall, they lacked complete maturity. Glochidial valves closed slowly or not at all when exposed to salt, and a greater amount of undifferentiated tissue was readily visible between the valves. Occasionally in the fall, the vitelline membrane of the former embryo was still surrounding the glochidium, further indicating the immaturity of glochidia extracted in the fall. Survival and growth of juvenile oyster mussels were poor when propagated in the fall, the juveniles rarely living beyond $60 \mathrm{~d}$. Maximum shell length of fall-propagated juveniles was less than 
$450 \mu \mathrm{m}$, reaching a plateau at a mean length of about $410 \mu \mathrm{m}$ at 8 weeks. These juveniles seemed incapable of growing to greater lengths, suggesting that somatic development of glochidia was incomplete at the time of their removal from the female mussel. Many of the juveniles produced from these glochidia did not pedal-feed, and those that did fed slowly and were not as vigorous as those produced in the spring. In contrast, oyster mussel glochidia were mature in the spring, exhibited multiple snapping responses when exposed to salt, lacked the vitelline membrane, and contained less undifferentiated tissue within the valves. Most of the juveniles produced from these glochidia were highly mobile and actively pedal-fed. The lower observed survival of laboratory-reared juvenile oyster mussels in spring 2003, may have been influenced by a greater percentage of immature glochidia contained in brooding females during the time (May) of their collection from the river. We speculate that increased numbers of immature glochidia may have been the result of substantially lower than normal water temperatures that are known to have occurred in the Clinch River in spring 2003 (see Liberty 2005 for temperature data). However, overall survival and growth of juvenile oyster mussels propagated in the spring of year were much greater, and the juveniles that survived to $60 \mathrm{~d}$ were healthy and vigorous. Thus, glochidia of oyster mussels from the Clinch River apparently are mature and suitable for propagation only in the spring.

The oyster mussel glochidia probably need to be brooded in the gills of the adult female until the time when she is ready to release the brood by displaying her mantle pad as water temperatures increase in the river. Warmer spring temperatures presumably allow glochidia to complete their development and become viable and ready for release to host fish. Though the process is poorly understood, we hypothesize that water temperature is a major factor controlling maturation of glochidia. Temperature-dependent maturation rates of glochidia likely vary among mussel species and are affected by life history variables, such as the length of time glochidia are brooded in the gill marsupia, for example, bradytictic (winter brooders) versus tachytictic (summer brooders). Bradytictic species typically spawn in the late summer and fall, and glochidia are brooded in the marsupial gills of the female throughout the winter until release the following spring and summer. Conversely, tachytictic species spawn in late spring and summer, brood their glochidia for a short time period, and then release glochidia in the same summer.

Determining the amount of time or the degreedays required for glochidia to mature is necessary for successful propagation of a mussel species (Beaty and Neves 2004). In this study, a significant proportion of the glochidia brooded in rainbow mussels (bradytictic) was sufficiently mature in the fall to successfully transform and culture. Conversely, brooded glochidia of oyster mussels (bradytictic) lacked sufficient maturity for fall propagation. We have observed this in other endangered mussel species as well, such as fanshell Cyprogenia stegaria, dromedary Dromus dromas, littlewing pearlymussel Pegias fabula, and purple bean Villosa perpurpurea and in common species, such as mountain creekshell $V$. vanuxemensis (Jones and Neves 2002; Jones et al. 2004; Jones unpublished data). Female rainbow mussels display their mantle lures primarily at night and over a longer period throughout the year, implying that this mussel species is more variable in maturation and seasonal release of its glochidia. In the Clinch River, female oyster mussels display their mantlepads fully only in the spring. The majority of females begin displaying and releasing glochidia in April, typically peaking from late April to midMay and finishing by late May to early June. However, the timing and duration of the female display and glochidial release period varies from year to year and appears to be related to seasonal water temperatures. The earliest we have observed these females fully displaying is March, but this seems to occur in years with mild winters and ensuing warm temperatures early in the spring. The latest we have observed females displaying is early $\mathrm{Au}-$ gust.

Glochidia in the water tubes of the outer gills of brooding female mussels (subfamily Lampsilinae) appear to exhibit various degrees of maturity. In oyster mussels, mature glochidia are probably contained near the distal end of the water tubes, where they can be released through distal pores while the female is displaying. The least mature glochidia are probably contained near the basal end of the water tubes. The hypothesis of gradation of maturity of glochidia within water tubes of the marsupial gill, though untested, is not without precedent. For example, mature glochidia were contained at the distal end of conglutinates of fanshell, and only embryos resided at the basal end (Jones and Neves 2002). When a female oyster mussel first begins to display in the spring, it is unlikely that her entire glochidial brood is mature 
and ready for release. Rather, the brood continues to mature as she is displaying, when the mature glochidia near the distal ends of the water tubes are released. After years of collection and examination of hundreds of gravid oyster mussels in spring, we have observed that glochidia are first released and emptied from the posterior water tubes. When a female is nearly spent, it is always the last few water tubes located in the anterior portion of the gill that contain glochidia. In late summer and early fall when oyster mussel females spawn and begin to fill their gills with eggs of a new brood, they do so by filling the posterior water tubes first. These observations suggest a gradation of the percentage of mature glochidia from the posterior to anterior region of the marsupial gill. The first eggs or embryos transported to the posterior region of the gill are probably fertilized sooner and brooded longer in the warm waters of late summer and early fall. Thus, these embryos mature sooner and are ready for release earlier than those transported to the gills later in the brooding season.

Understanding the final maturation process of glochidia is critical to propagation because it dictates when to harvest glochidia with the greatest percentage of maturity from a female mussel. If gravid oyster mussel females are collected early in spring when they are just beginning to display, we have found it useful to hold them in a hatchery raceway or recirculating tank system for 1-2 weeks at $21-23^{\circ} \mathrm{C}$ to allow the brood to finish maturation. However, the females need to be carefully monitored to ensure that they are not releasing their glochidia too quickly. We have observed that survival of juvenile mussels typically increases by more than $20 \%$ when glochidia are harvested in this manner or from females collected in the river later in the glochidial release period in mid-May to early June. Moreover, in marine bivalves, conditioning broodstock has been successfully practiced to increase larval survival (Lannan 1980b). Obtaining mature glochidia is an empirical process, yielding an improved understanding of the reproductive biology of a species. Thus, hatchery managers and researchers need to be aware that maturity of glochidia can affect the results of propagation efforts and experimental work. Additional factors probably influence quality of glochidia other than maturity, such as various ontogenetic and environmental factors affecting the larval brood of individual female mussels.

\section{Influence of Fine Sediment}

Survival and growth of juvenile oyster mussels and rainbow mussels were greatly enhanced by the addition of fine sediments to the culture dishes. Growth and survival of juvenile mussels cultured without sediment was so poor that long-term culture failed. Previous studies (Gatenby et al. 1996; O'Beirn et al. 1998) also showed that sediment significantly increases culture success of juvenile freshwater mussels. However, the biological role of river sediments in laboratory culture of juvenile mussels remains unclear. Gatenby et al. (1996) and references therein suggested that fine sediments enhance juvenile mussel digestion by providing bacterial flora to the gut and a grinding substrate for the crystalline style, both of which may assist the breakdown of food particles. These authors also stated that sediment facilitated collection of food particles by pedal-feeding juveniles. O'Beirn et al. (1998) believed that sediment provides additional food resources for juveniles and a substrate for orienting themselves spatially while filter-feeding. The sand substratum used in this study also should have provided a physical medium for juveniles to orient themselves while feeding, but survival and growth in those conditions were still poor. Thus, we find it unlikely that sediment provides merely a physical medium for juveniles to orient themselves while feeding, but rather is an essential biological component in their feeding ecology. Research by Nichols and Garling (2000, 2002) has implicated bacteria as an important food resource and dietary requirement for unionids. Our data corroborate their results, namely, that successful culture of juveniles was possible only in a sediment substratum where a robust bacterial flora and other microorganisms are more likely to flourish. Survival and growth were poor for juveniles held in the sand or no substrate treatments, despite the fact that juveniles were ingesting the algae feed. Therefore, the combination of algae and sediment is seemingly synergistic in providing basic dietary requirements of juvenile mussels.

Sediment and associated microflora probably serve several important functions, such as aiding in digestion, providing a nutritional resource, protecting from predators, facilitating feeding orientation, and enhancing hygiene. With respect to hygiene, juvenile mussels cultured in our bare-bottom sieve dishes contained greater amounts of attached epiphytes (e.g., fungi and algae) growing on the shell. Epiphytes observed growing around the ventral margin of the shell probably interfered 
with their ability to feed. In contrast, shells of juveniles cultured in sediment appeared clean and free of epiphytes.

Though sediment seems to be required for laboratory culture of juvenile mussels, it needs to be prepared properly before use. Best results were obtained by sieving to a particle size that allows for easy handling and sorting of juvenile mussels during their culture. Most newly metamorphosed juvenile mussels are about $150-300 \mu \mathrm{m}$ at age 0; therefore, we typically sieve sediments to less than 200-300 $\mu \mathrm{m}$. Moreover, it is critical that sediments are autoclaved; $20 \mathrm{~min}$ above $120^{\circ} \mathrm{C}$ is sufficient. This heat treatment kills invertebrate predators such as flatworms, hydra, and various dipteran larvae, which can induce mortality by eating or encasing juvenile mussels, and a plethora of benthic zooplankters, which can disturb juvenile mussels while they are feeding. Because autoclaved sediments typically emit a foul odor, presumably from dead and decaying organic material, it is best to heavily aerate the sediments for at least a few days before use. Aeration will remove the odor and help oxidize organics and reduce organic acid content. We continued aeration for 1-2 weeks until sediments became lighter in color, presumably from oxidation of organic material. Interestingly, the lighter color of "oxidized" sediments is similar to the coloration of natural river sediments found in highly oxygenated riffles and runs that are prime mussel habitat.

\section{Comparison of Algae Diets}

Both $N$. oculata and N. oleoabundans promoted excellent growth and survival of juvenile oyster mussels and rainbow mussels; therefore, both of these algal species are seemingly adequate for the initial culture of young mussels. Our results corroborated research conducted by Gatenby et al. (1997) and O'Beirn et al. (1998), who determined that microalgae such as $N$. oleoabundans are appropriate diets for culture of juvenile mussels. Both $N$. oculata and $N$. oleoabundans range in size from about 3 to $10 \mu \mathrm{m}$ and are of sizes easily ingested by newly metamorphosed juveniles (Beck and Neves 2003). Lasee (1991) determined that 2-d-old pocketbook Lampsilis ventricosa have a mouth size of about $16 \mu \mathrm{m}$ and an esophagus about $6 \mu \mathrm{m}$ long. During our study, the guts of juvenile mussels would become green in color $1-2 \mathrm{~d}$ after being fed, indicating that they easily ingested the cells of both microalgal species. Juvenile rainbow mussels cannot ingest larger algal species, such as Scenedesmus quadricauda (size range $\sim 22-45$ $\mu \mathrm{m}$; Beck and Neves 2003); guts of juveniles fed S. quadricauda were empty, when offered cells of this larger species. The species N. oculata contains high concentrations of lipids (Hoff and Snell 1999; Zou et al. 2000), especially polyunsaturated fatty acids, which are important nutritional constituents for promoting growth and survival of juvenile mussels (Gatenby et al. 1997) and young marine bivalves (Hoff and Snell 1999). This algal species has been used widely as a food resource for larval rearing of various organisms (Hoff and Snell 1999). The alga $N$. oleoabundans contains high concentrations of protein, which are beneficial for the nutritional health of juvenile mussels (Gatenby et al. 2003). Feeding these microalgal species together should provide a more complete diet for mussel rearing. A diet of various species of algae was recommended by Gatenby et al. (1997), who reported greater survival and growth of rainbow mussel juveniles reared on a mixed diet of three algal species. Mixed algal diets are frequently used in marine aquaculture to improve grow-out of various bivalves (Gatenby et al. 2003). Finally, we found that $N$. oleoabundans was more difficult to culture in large quantities than $N$. oculata, taking longer to culture to high cell densities and proving more prone to "crash" for unknown reasons.

\section{Conclusions}

Continued improvements in propagation and culture technology for rearing endangered juvenile mussels are necessary for several reasons. First, propagation of juvenile mussels is advantageous because large numbers can be produced from relatively few adults. For some species, collecting gravid females for propagation can be challenging, but from a few adults thousands of juveniles can be produced, outweighing any recovery gains made by relocating a small number of adults. Second, culturing juvenile mussels allows a measure of quality control before their release to the wild. Growth and survival, juvenile vigor, diseases, and other measures of batch quality can be assessed and monitored. Tracking such measures will lead to insights regarding factors driving the success or failure of juvenile mussels released to the wild. Third, the ability to successfully culture juvenile mussels in the laboratory for 1-2 months or longer allows for control of when and where juveniles are released. It is important that juveniles be released under low flow conditions to allow successful settlement at optimal sites on the river bottom. Ideally, releases may be best done when spring water levels subside in early to midsummer. Extended 
culture increases the size and weight of juveniles, allowing them to sink and settle more quickly and thus improving survivability. Finally, understanding the factors controlling juvenile mortality will require that culturists simultaneously test for effects of intrinsic factors (e.g., maturity of glochidia) and extrinsic factors (e.g., rearing environment).

As propagation becomes a more viable tool to help restore mussel species, an increased awareness and concern over population genetic issues is warranted. Attention should be focused on the following: (1) molecular and quantitative genetic analysis of potential source populations to establish the existence and adaptive significance of evolutionarily significant units within species (Hard 1995; Mayden and Wood 1995), (2) preserving the genetic integrity of cultured populations by minimizing any adaptive genetic changes incurred in progeny produced and reared in captivity (Miller and Kapuscinski 2003; Neves 1997), and (3) the potential for reduction of the genetically effective population size $\left(N_{e}\right)$ that can result from breedingrelease programs aimed at supporting natural populations (Ryman and Laikre 1991). Operational guidelines for incorporating genetic principles should be developed.

\section{Acknowledgments}

We thank everyone who helped us complete the laboratory and fieldwork for this study. The following individuals made our study possible: Steve Ahlstedt, Richard Biggins, Mark Fagg, Joe Ferraro, Jeff Flynn, John McLeod, and Mike Pinder. This study was funded by the Tennessee Wildlife Resources Agency, Nashville, Tennessee, and the U.S. Fish and Wildlife Service, Asheville, North Carolina. Eric Hallerman, Department of Fisheries and Wildlife Sciences, Virginia Polytechnic Institute and State University, Blacksburg, Virginia, provided comments on an earlier version of this manuscript.

\section{References}

Ahlstedt, S. A. 1991. Twentieth-century changes in the freshwater mussel fauna of the Clinch River (Tennessee and Virginia). Walkerana 5:73-122.

Beaty, B. B., and R. J. Neves. 2004. Use of a natural river water flow-through culture system for rearing juvenile freshwater mussels (Bivalvia: Unionidae) and evaluation of the effects of substrate size, temperature, and stocking density. American Malacological Bulletin 19:15-24.

Beck, K. M. 2001. Development of an algal diet for rearing juvenile freshwater mussels. Master's thesis.
Virginia Polytechnic Institute and State University, Blacksburg.

Beck, K. M., and R. J. Neves. 2003. An evaluation of selective feeding by three age-groups of the rainbow mussel Villosa iris. North American Journal of Aquaculture 65:203-209.

Boudry, P., B. Collet, F. Cornette, V. Hervouet, and F. Bonhomme. 2002. High variance in reproductive success of the Pacific oyster (Crassostrea gigas, Thunberg) revealed by microsatellite-based parentage analysis of multifactorial crosses. Aquaculture 204:283-296.

Fisher, G. R., and R. V. Dimock, Jr. 2002a. Ultrastructure of the mushroom body: digestion during metamorphosis of Utterbackia imbecillis (Bivalvia: Unionidae). Invertebrate Biology 121:126-135.

Fisher, G. R., and R.V. Dimock, Jr. 2002b. Morphological and molecular changes during metamorphosis of Utterbackia imbecillis (Bivalvia: Unionidae). Journal of Molluscan Studies 68:159-164.

Gaffney, P. M., C. M. Bernat, and S. K. Allen, Jr. 1993. Gametic incompatibility in wild and cultured populations of the eastern oyster, Crassostrea virginica (Gmelin). Aquaculture 115:273-285.

Gatenby, C. M., R. J. Neves, and B. C. Parker. 1996. Influence of sediment and algal food on cultured juvenile freshwater mussels. Journal of the North American Benthological Society 15:597-609.

Gatenby, C. M., B. C. Parker, and R. J. Neves. 1997. Growth and survival of juvenile rainbow mussels, Villosa iris (Lea, 1829) (Bivalvia: Unionidae), reared on algal diets and sediment. American Malacological Bulletin 14:57-66.

Gatenby, C. M., D. M. Orcutt, D. A. Kreeger, B. C. Parker, V. A. Jones, and R. J. Neves. 2003. Biochemical composition of three algal species proposed as food for captive freshwater mussels. Journal of Applied Phycology 15:1-11.

Hard, J. J. 1995. A quantitative genetic perspective on the conservation of intraspecific diversity. Pages 304-326 in J. Nielsen and D. Powers, editors, Evolution and the aquatic ecosystem. American Fisheries Society, Symposium 17, Bethesda, Maryland.

Hoff, F. H., and T. W. Snell. 1999. Plankton culture manual, 5th edition. Florida Aqua Farms, Inc. Dade City, Florida.

Jones, J. W., R. J. Neves, S. A. Ahlstedt, and R. A. Mair. 2004. Life history and propagation of the endangered dromedary pearlymussel, Dromus dromas (Bivalvia: Unionidae). Journal of the North American Benthological Society 23:515-525.

Jones, J. W., and R. J. Neves. 2002. Life history and propagation of the endangered fanshell pearlymussel, Cyprogenia stegaria Rafinesque (Bivalvia: Unionidae). Journal of the North American Benthological Society 21:76-88.

Lannan, J. E. 1980a. Broodstock management of Crassostrea gigas, I. Genetic and environmental variation in survival in the larval rearing system. Aquaculture 21:323-336.

Lannan, J. E. 1980b. Broodstock management of Cras- 
sostrea gigas, II. Broodstock conditioning to maximize larval survival. Aquaculture 21:337-345.

Lannan, J. E. 1980c. Broodstock management of Crassostrea gigas, III. Selective breeding for improved larval survival. Aquaculture 21:347-351.

Lannan, J. E. 1980d. Broodstock management of Crassostrea gigas, IV. Inbreeding and larval survival. Aquaculture 21:353-356.

Lasee, B. A. 1991. Histological and ultrastructural studies of larval and juvenile Lampsilis (Bivalvia) from the upper Mississippi River. Doctoral dissertation. Iowa State University, Ames.

Liberty, A. 2005. An evaluation of the survival and growth of juvenile and adult freshwater mussels at the Aquatic Wildlife Conservation Center, Marion, Virginia. Master's thesis. Virginia Polytechnic Institute and State University, Blacksburg.

Mayden, R. L., and R. M. Wood. 1995. Systematics, species concepts, and the evolutionarily significant unit in biodiversity and conservation biology. Pages 58-113 in J. Nielsen and D. Powers, editors. Evolution and the aquatic ecosystem. American Fisheries Society, Symposium 17, Bethesda, Maryland.

Miller, L. M., and A. R. Kapuscinski. 2003. Genetic guidelines for hatchery supplementation programs. Pages 329-356 in E. M. Hallerman, editor. Population genetics: principles and practices for fisheries scientists. American Fisheries Society, Bethesda, Maryland.

Nelson, J. S., E. J. Crossman, H. Espinosa-Perez, L. T. Findley, C. R. Gibert, R. N. Lea, and J. D. Williams. 2004. Common and scientific names of fishes from the United States, Canada, and Mexico, 6th edition. American Fisheries Society, Special Publication 29, Bethesda, Maryland.

Neves, R. J. 1997. A national strategy for the conservation of native freshwater mussels. Pages 1-10 in K. S. Cummings, A. C. Buchanan, C. A. Mayer, and T. J. Naimo, editors. Conservation and management of freshwater mussels, II: Initiatives for the future. Upper Mississippi River Conservation Committee, Rock Island, Illinois.

Neves, R. J., A. E. Bogan, J. D. Williams, S. A. Ahlstedt, and P. W. Hartfield. 1997. Status of aquatic mollusks in the southeastern United States: a downward spiral of diversity. Pages 43-85 in G. W. Benz and D. E. Collins, editors. Aquatic fauna in peril: the southeastern perspective. Southeast Aquatic Research Institute, Special Publication 1, Decatur, Georgia.

Neves, R. J. 1999. Conservation and commerce: management of freshwater mussel (Bivalvia: Unionoidea) resources in the United States. Malacologia 41:461-474.
Nichols, S. J., and D. Garling. 2000. Food web dynamics and trophic-level interactions in a multispecies community of freshwater unionids. Canadian Journal of Zoology 78:871-882.

Nichols, S. J., and D. Garling. 2002. Evaluation of substitute diets for live algae in the captive maintenance of adult and subadult Unionidae. Journal of Shellfish Research 21:875-881.

O’Beirn, F. X., R. J. Neves, and M. B. Steg. 1998. Survival and growth of juvenile freshwater mussels (Unionidae) in a recirculating aquaculture system. American Malacological Bulletin 14:165-171.

Ricciardi, A., and J. B. Rasmussen. 1999. Extinction rates of North American freshwater fauna. Conservation Biology 13:1220-1222.

Ryman, N., and L. Laikre. 1991. Effects of supportive breeding on the genetically effective population size. Conservation Biology 5:325-329.

SAS Institute. 2001. Statistical analysis system. SAS Institute, Cary, North Carolina.

Tankersley, R. A. 2000. Fluorescence techniques for evaluating the lipid content of larval and juvenile mussels. Pages 115-125 in R. A. Tankersley, D. Warmolts, G. T. Watters, and B. Armitage, editors. Freshwater mollusk symposia proceedings, part I. Proceedings of the Conservation, Captive Care, and Propagation of Freshwater Mussels Symposium. Ohio Biological Survey, Columbus.

Turgeon, D. D., J. F. Quinn, Jr., A. E. Bogan, E. V. Coan, F. G. Hochberg, W. G. Lyons, P. M. Mikkelsen, R. J. Neves, C. F. E. Roper, G. Rosenberg, B. Roth, A. Scheltema, F. G. Thompson, M. Vecchione, and J. Williams. 1998. Common and scientific names of aquatic invertebrates from the United States and Canada: mollusks, 2nd edition. American Fisheries Society, Special Publication 26, Bethesda, Maryland.

Williams, J. D., M. L. Warren, Jr., K. S. Cummings, J. L. Harris, and R. J. Neves. 1993. Conservation status of freshwater mussels of the United States and Canada. Fisheries 18(9):6-22.

Zale, A. V., and R. J. Neves. 1982. Fish hosts of four species of lampsiline mussels (Mollusca: Unionidae) in Big Moccasin Creek, Virginia. Canadian Journal of Zoology 60:2535-2542.

Zimmerman, L. L., and R. J. Neves. 2003. Control of predacious flatworms Macrostomum sp. in culturing juvenile freshwater mussels. North American Journal of Aquaculture 65:28-32.

Zou, N., C. Zhang, Z. Cohen, and A. Richmond. 2000. Production of cell mass and eicosapentaenoic acid (EPA) in ultrahigh cell density cultures of $N$. oculata sp. (Eustigmatophyceae). European Journal of Phycology 35:127-133. 